to publish. It is a valuable custom that all manu. scripts have to be communicated through a Fellow of the Society, who should be able to criticize the presentation and act, to some extent, as referee before consenting to act as sponsor.

Mr. P. J. Edmonds (Publishers Association, Technical Group) applauded Prof. Thorpe's arrangements for periodic meetings of editors, production staff and printers; he thought that many of the problems with which the Council is concerned arise through imperfect comprehension between those responsible for the scientific, literary, technical and financial aspects of publication. Whilo appreciating $\mathrm{Mr}$. Bacharach's feelings about the proliferation of books and journals, he thought that the remedy lies with librarians and library committees, who should be more selective. Mrs. Olga Kennard (editor, Crystul Data) said that the publication of candidly critical reviews in reputable journals is the greatest safoguard, but Dr. A. J. Evans (librarian, School of Pharmacy, London) complained that even though economic considerations force librarians to be selective, reviews often appear too late to bo of much assistance to them.
A. V. S. DE REUCK

\title{
THE FULMER RESEARCH INSTITUTE
}

$\mathrm{A}^{\mathrm{N}}$ $\mathrm{N}$ open day was held at the Fulmer Research Institute on June 7. The occasion marked tho fiftcenth anniversary of the Institute's foundation and the completion of laboratory extensions.

The chairman, Mr. W. R. Merton, introduced the principal guest, Mr. Denzil Freeth, Parliamentary Secretary for Science, who emphasized in a short address that the Ministry did its best to persuade industry that scientific and technological rescarch is not only worth while, but is in fact economical and vital for progress, expansion and prosperity. The reply was often that it was too costly to set up extensive laboratories and engago specialized staff to carry out particular pieces of research. This was true, but it was to overcome this objection and to meet these needs that establishments where confidential sponsored research could be undertaken had been set up. Mr. Freeth eongratulated Fulmer on the high quality of its staff and specialized facilities and said that he envisaged a great future for sponsored rescarch.

The new extensions to the Physies and Physical Metallurgy Laboratories provide approximately 3,000 sq. ft. of additional laboratory space, about half of which is basement accommodation. Provision is made in the extensions to the Physical Metallurgy Laboratory for handling toxic materials, and in the oxtonsions to the Physics Laboratory for housing additional X-ray diffraction units, together with a new EM6 electron microscopc.

In recent yoars, a high proportion of the work of the Physies and Physical Metallurgy Sections has been concerned with metals of importanco in the field of nuclear power, such as uranium, zirconium and beryllium. In unalloyed uranium the orthorhombic $\alpha$-phase is stable up to $660^{\circ} \mathrm{C}$. and the anisotropic nature of the $\alpha$-phase can result in dimensional instability of fuel elements in the reactor. One way of avoiding this is by quenching dilute alloys from the $\beta$-phase region to give a fine-grained structure, free from preferred orientation. The mode and kineties of transformation of the $\beta$-phaso are being investigated at Fulmer using hot hardnoss, thermal analysis, X-ray diffraction and metallographic techniques; the structure of the $\beta$-phase is also being studied.

Another approach for overeoming fuel-element instability is to alloy the uranium to a greater extent to give the eubie isotropic $\gamma$-phase at fuel temperatures. Basic information pertaining to the processes oceurring when fuel elements are cooled has been obtained at the Institute by querching varions alloys at different cooling-rates to give a sequence of transformation struetures between $\gamma$ and $\alpha$. The physical properties, kinetics and mechanism of transformation of these alloys have been studied.

Zirconium and its alloys are important as canning and constructional materials in water-moderater reactors. The recent announcement by the United Kingdom Atomic Energy Authority of the projected development of the steam generating heavy water reactor makes the Institute's work on zirconium of particular interest. The reactive nature of zirconium has necessitated the design of a high-vacuum, hightempcrature X-ray camera for structural studies at temperatures up to $1,000^{\circ} \mathrm{C}$. The embrittling 'omega' phase has been studied in a number of binary zireonium systems and the nature of the omega phase and its derivation from the high-tomperature body-centred cubic structure of zirconium have been determined.

Beryllium has important applications as a nuclear and structural material by virtue of its low neutronabsorption cross-section and high strength/weight ratio; but its present use is limited by its inherent brittleness. The deformation characteristics of beryllium have been studied at Fulmer, and the present work is concerned with the effect of minute amounts of impurities in beryllium. It is thought, that some impurities form precipitation-hardening systems with beryllium and the mechanism of precipitation in beryllium having an artificially high iron content is being studied by X-ray diffraction. A specially designed $\mathrm{X}$-ray diffraction camera for studying the structure of liquid metals was demonstrated. Recent work has shown that the structure of liquid tin can be regarded as consisting of tetrahodra of grey tin in a random matrix. Work on alloy systems has shown that liquids of certain alloys, for example, gold-tin, copper-tin and gold-gallium, exhibit a high degree of order, and $\mathrm{X}$-ray diffraction work on these systems is being supplernented by density studies.

Chromium is attracting considerable interest as a high-ternperature material, but suffers from brittleness at room temperature. This brittleness is thought to be associated with the presence of impurities and tho Institute's fluoride process for electrodepositing purity chromium (10 p.p.m. nitrogen, 200 p.p.m. oxygen and 80 p.p.m. hydrogen) is an important contribution in this sphere. Exhibits included a 4-in. diameter chromium ingot prepared at Fulmer by melting electro-doposited flakes in a consumable ure furnace, and extruded chromium bars. 
Use of molybdenum as a high-temperature material is restricted because of the ease with which it oxidizes and the volatility of its oxide. At Fulmer, molybdenum is being coated with boron and silicon in an attempt to overcome this problem. The sample to be coated is placed in a graphite reaction vessel surrounded with small pieces of boron (or silicon). The vessel is heated to an appropriate temperature and a slow stream of boron (or silicon) halide is passed through the system. A lower halide is formed and reacts with the surface of the sample to form a boron or silicon coating. Work is also in progress on the coating of another high-temperature material, graphite, with tungsten. The graphite is heated in a stream of hydrogen into which tungsten hexafluoride is injected and a tungsten coating is obtained.

The results of work on the causes of 'feathering'an extrusion defect--in lead-antimony cable sheathing were shown. The defect was found to be caused by melting of segregates of low melting-point during extrusion and was overcome in the laboratory by use of a central chill during extrusion.

Work at the Thornton Research Centre of Shell Research, Ltd., and at Fulmer has shown that the resistance of pearlitic cast irons of the type used for cylinder liners of marine Diesel engines to corrosion by condensed sulphuric acid is related to the silicon content. This work has aroused considerable interest since corrosion of this type is thought to be a major factor in the wear of engines. Recent work at the Institute has been concerned with the effect of copper and nickel additions on the corrosion resistance of these irons. The Corrosion Laboratory exhibits included accounts of work on corrosion fatigue, stress corrosion and the effect of anodizing variables on the corrosion resistance of anodized aluminium. The corrosion-fatigue properties of high-strength aluminium-zinc-magnesium alloys are being studied with electrochemical polarization of the specimen. It has been shown that increased fatigue lives can be produced by electrochemical polarization and various stages in the potential/time curves can be related to different cracking mechanisms. The work is valuable in contributing to an understanding of the influence of sacrificial anodic coatings in corrosion fatigue. A 'Slipping-clutch' axial-load fatigue machine of the National Physical Laboratory type, designed and built in the Institute's laboratories, was an itom of special interest among exhibits of apparatus, and arrangements have been made to build these relatively inexpensive machines under licence for sale to outside laboratories.

The discovery several years ago of superconducting alloys which exhibit superconductivity at very much higher critical fields than had previously been achieved was an event of considerable importance. These alloys are now being considered for such applications as power transmission and for achieving high magnetic fields for nuclear fusion experiments. The staff of the Process Metallurgy Section have successfully fabricated the superconducting alloys $\mathrm{Nb}_{3} \mathrm{Sn}, \mathrm{V}_{3} \mathrm{Ga}$ and $\mathrm{Nb} / \mathrm{Zr}$, which tend to be brittle and difficult to handle, into a variety of forms required for eloctrical measurements.

The Physical Chemistry Section specializes in the determination of thermodynamic data of high accuracy; exhibits included accounts of calorimetric measurements of heats of formation of inorganic fluorides, chlorides, bromides, nitrides, uranium alloys and various binary metal oxide systems. Boron trifluoride is of interest as a rocket propellent because of its high heat of formation. Boron monofluoride can also be formed in reactions involving boron and fluorine, and the stability of this radical is being studied. At high temperatures, radiation from gases plays an important part in heat transfer and emissivity data are therefore important for the design of equipment. An apparatus designed and constructed at the Institute for measuring emissivities of gases at temperatures up to $1,000^{\circ} \mathrm{C}$. was demonstrated in the Physical Chemistry Section.

The wear resistance of thin metal films for use in potentiometers is being studied at Fulmer. The films are produced by evaporating nichrome alloy on to a glass substrate. Potentiometer conditions are simulated by mounting the film on a turntable and making contact with a sliding probe. Results of the present work show that the mechanical wear depends on the current in the sliding contact and the design of the probe and may be reduced by limiting the maximum voltage at the contact.

The Institute has an Associated Electrical Industries $E M 3 A$ electron microscope and an EM6 instrument is on order. Various types of replica techniques were demonstrated in the electron microscope section and emphasis was laid on the use of reflexion techniques for examining solids. Recent uses of the microscope include a study of the build-up of scale in oil-fired boilers. Electron micrographs showed how fine oxide needles are first formed on metallic surfaces. These afterwards grow and entrap ash particles forming a basis for the build-up of scale. Electron micrographs were also shown of razor-blade edges, evaporated metal films and metal fracture surfaces, and there were examples of the use of the electron microscope in the study of precipitation in thin films.

Recent research on the mechanism of age-hardening in aluminium alloys, a field in which the Institute's work is widely known, has been concerned with the effects of quenching and of heating to ageing temperature on the ageing characteristics of high-purity aluminium-copper alloys containing small ternary additions such as indium and magnesium. A study of the influence of small ternary additions in magnesium-lead, aluminium-magnesium and various copper-base alloy systems has indicated that their effects can be rationalized in terms of atomic size factor, particularly where they modify the distribution of precipitate rather than its structure, and where they influence grain boundary phenomena and over-ageing.

Creep fracture is often associated with the linkage of grain-boundary cavities formed during creep. Work on the influence of small binary additions on cavity formation was exhibited. Addition of titanium to chromium results in a finer distribution of cavities than in unalloyed chromium, and vanadium additions appear to prevent cavitation. Creep cavities are frequently nucleated at non-metallic inclusions and the effect of small solute additions on formation of cavities in copper is being studied using high purity copper free from non-metallic inclusions.

In recent work on the deformation characteristics of copper-zine alloys, yield stresses of alloys with varying zine contents and grain sizes have been measured over a range of temperatures; the structures of slip lines in alloys of varying zine content have been studied by electron microscopy. The results indicate that the changes in slip structure and the solid-solution hardening which occur on addition of zine to copper can be attributed to segregation of zine atoms to dislocations.
J. COLF: 